\title{
Mucus extravasation and retention phenomena: a 24-year study
}

\author{
Alethea M Hayashida', Daniel CZ Zerbinatti ${ }^{1}$ Ivan Balducci², Luiz Antonio G Cabral and Janete D Almeida*3
}

\begin{abstract}
Background: Mucoceles are benign lesions related to the minor salivary glands and their respective ducts frequently affecting oral structures which are generally asymptomatic. Mucoceles are generally characterized by swollen nodular lesions preferentially located on the lower lip and differ from the so-called ranulas, which are lesions located on the floor of the mouth and related to the sublingual or submandibular glands.
\end{abstract}

Methods: The objective of the present study was to analyze data such as age, gender, race and site of the lesion of 173 mucocele cases diagnosed at the Discipline of Stomatology, São José dos Campos Dental School, UNESP, over a period of 24 years (April 1980 to February 2003).

Results: Of the 173 cases analyzed, 104 (60.12\%) were females and 69 (39.88\%) were males. Age ranged from 4 to 70 years (mean \pm SD: $17 \pm 9.53)$ and most patients were in the second decade of life $(n=86,49.42 \%)$; white $(n=124$, $71.68 \%)$. The lower lip was the site most frequently affected by the lesions $(n=135,78.03 \%)$, whereas the lowest prevalence was observed for the soft palate, buccal mucosa, and lingual frenum.

Conclusion: In this study, mucoceles predominated in white female subjects in the second decade of life, with the lower lip being the most frequently affected site.

\section{Background}

Mucoceles are common minor salivary gland lesions clinically characterized by single or multiple, spherical, fluctuant nodules which are generally asymptomatic $[1,2]$. They are believed to result from mechanical trauma to the excretory duct of the salivary glands, causing duct transection or rupture, with consequent extravasation of mucin to the connective tissue stroma (mucus extravasation phenomenon, MEP). In addition, mucus might be retained in the duct and/or acinus as a result of duct obstruction (mucus retention phenomenon, MRP). MRP are less frequent and are seen particularly in the elderly [3-5].

Mucus extravasation triggers a secondary inflammatory reaction predominantly consisting of mononuclear cells in surrounding connective tissue, followed by a granulation tissue-type reaction that culminates in the formation of a fibrous capsule around the mucin deposit,

\footnotetext{
* Correspondence: janete@fosjc.unesp.br

${ }^{3}$ Department of Biosciences and Oral Diagnosis, São José dos Campos Dental School, São Paulo State University (UNESP), São José dos Campos, São Paulo, Brazil

Full list of author information is available at the end of the article
}

conferring a cyst-like aspect to the lesion [6,7]. The diameter of mucoceles ranges from a few millimeters to centimeters $[7,8]$. Many patients report the periodic discharge of viscous fluid from the lesion.

According to several studies, the lower lip is the region most affected by mucoceles [2,6,9-15]. However, rare cases of mucoceles involving the upper lip, palate, retromolar region, buccal mucosa, lingual frenum, and dorsal tongue have been reported [5,8,11-16].

Ranula designates mucoceles located on the floor of the mouth [17]. The name is derived from the Latin word "rana" (meaning frog) because of its resemblance with the underbelly of a frog $[1,2,5,6,8,9,11,13-15,18]$. Ranulas are generally related to the duct systems of the sublingual salivary glands and, less frequently, to the submandibular gland and minor salivary gland ducts of the floor of the mouth [1]. A ranula manifests as a cup-shaped fluctuant bluish swelling on the floor of the mouth. Ranulas tend to be larger than mucoceles located in other regions of the mouth, reaching some centimeters in diameter. Depending on size and location, patient may present external swelling and relate discomfort, interference with speech, mastication, and swallowing [11].

(c) 2010 Hayashida et al; licensee BioMed Central Ltd. This is an Open Access article distributed under the terms of the Creative Com:H Wed Central mons Attribution License (http://creativecommons.org/licenses/by/2.0), which permits unrestricted use, distribution, and reproduction in any medium, provided the original work is properly cited. 
The objective of the present study was to analyze cases of mucocele diagnosed between April 1980 and February 2003 at the Discipline of Semiology, São José dos Campos Dental School (FOSJC), UNESP, and to establish the prevalence of these lesions according to age, gender, race and site of ocurrence.

\section{Methods}

In a survey of the clinical records of the Discipline of Stomatology, Department of Biosciences and Oral Diagnosis, São José dos Campos Dental School, São Paulo State University, comprising the period between April 1980 and February 2003, 173 cases with a diagnosis of MEP or MRP were selected. Data regarding age, gender, race and site of the lesion were obtained from these records. The study was approved by the Ethics Committee of FOSJC-UNESP (protocol 037/2003 PH/CEP).

\section{Results}

Age ranged from 0 to 10 years in 46 (26.43\%) patients, from 11 to 20 years in 86 (49.42\%), from 21 to 30 in 22 (12.64\%), and $19(10.91 \%)$ subjects were older than 30 years, with a mean age of 17 years and a median age of 14 years $(\mathrm{StDev}=11.341 ;$ minimum $=4 ;$ maximun $=70 ; \mathrm{Q} 1$ = 10; $\mathrm{Q} 3=21$ ) (Figure 1).

Of the 173 cases studied, 104 (60.12\%) were females and $69(39.88 \%)$ were males. Regarding race, 124 subjects $(71,68 \%)$ were white, $45(26,01 \%)$ were black and four $(2,31)$ were of Asian origin.

Mucoceles were located on the lower lip in $78 \%$ of cases (Figure 2), on the ventral tongue in $9.83 \%$ (Figure 3), on the floor of the mouth in $9.25 \%$ (Figure 4), and on the soft palate, buccal mucosa (Figure 5) and lingual frenum in $0.58 \%$ each.

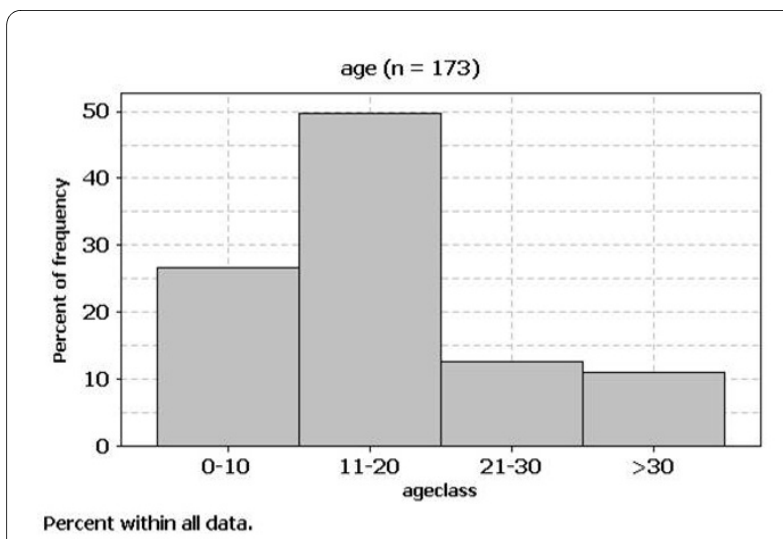

Figure 1 Distribution according to age of cases of mucoceles diagnosed between April 1980 and February 2003 at the Discipline of Stomatology Department of Biosciences and Oral Diagnosis, São José dos Campos Dental School, São Paulo State University

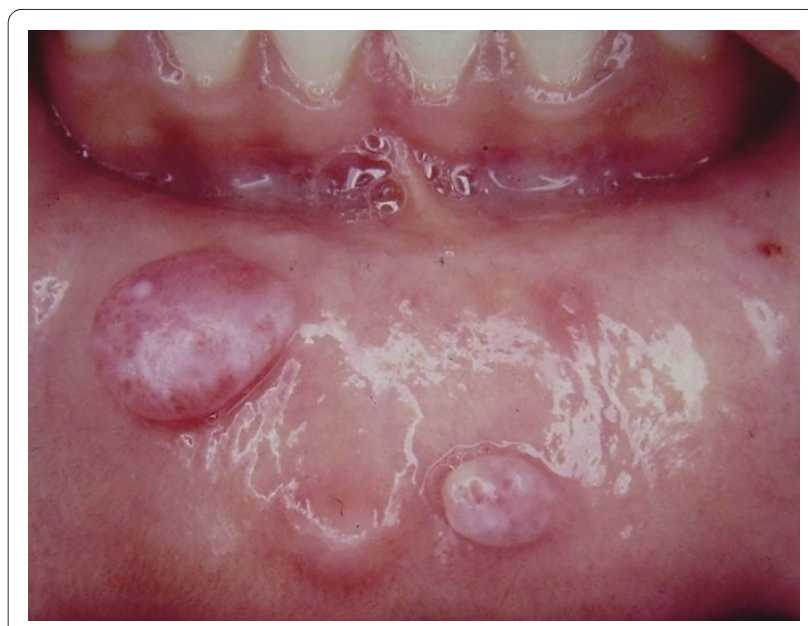

Figure 2 Turgid nodular lesions located on the lower lip

\section{Discussion}

In general, salivary gland diseases can be subdivided into neoplastic and non-neoplastic diseases. The latter category includes different diseases that pose a diagnostic and therapeutic challenge to the clinician because of their closely similar clinical presentation despite different etiologies such as reactional inflammatory processes, metabolic and immune disorders, infections, and iatrogenic responses. Thus, clinical knowledge of oral lesions, as well as the determination of aspects related to the etiopathogenesis of these lesions, is necessary for the correct diagnosis and for the indication of appropriate treatment [16].

When located on the ventral tongue, the differential diagnosis with lymphangioma must be considered. de Camargo Moraes et al.[19] state that mucocele of the

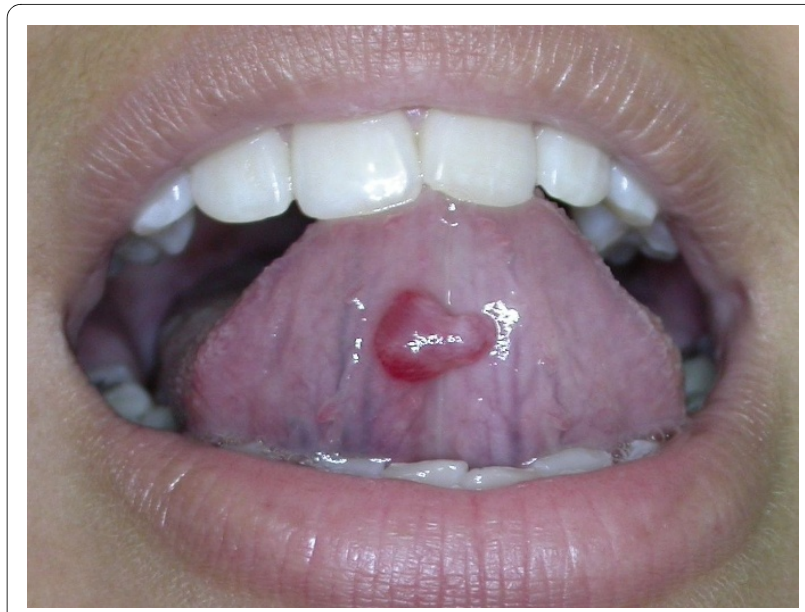

Figure 3 Mucocele of the gland of Blandin-Nuhn (ventral tongue). Pediculated turgid nodular lesion, measuring $3.0 \mathrm{~cm}$ in diameter. 


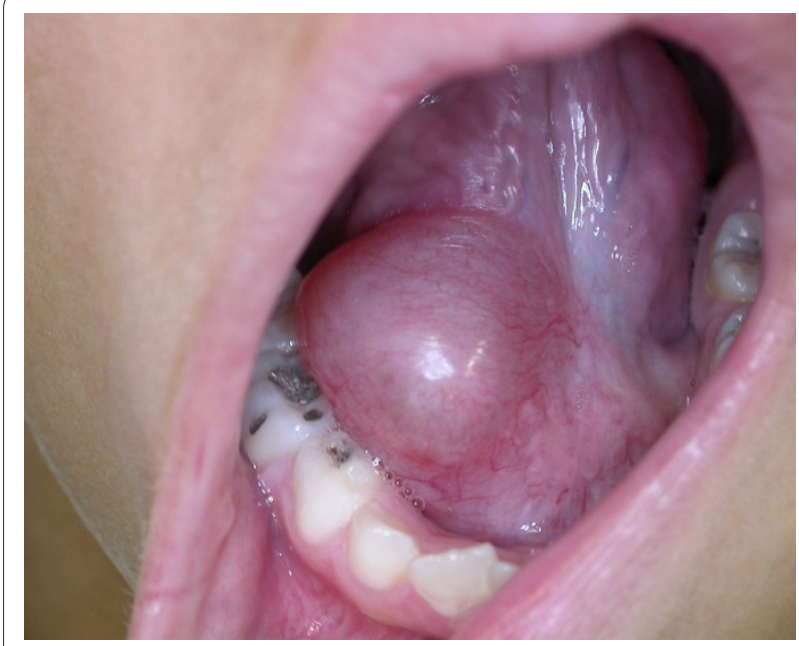

Figure 4 Asymptomatic turgid nodular lesion located on the floor of the mouth, measuring $4.0 \mathrm{~cm}$ in diameter.

gland of Blandin-Nuhn (ventral tongue) should not be considered rare. In their series, this type of mucocele was the second most frequent.

Lesions located in the soft palate and retromolar region are rare, but in the latter case the differential diagnosis with mucoepidermoid carcinoma should be considered.

Among the non-neoplastic pathological processes affecting the minor salivary glands, mucoceles are the most common in children and young adults, a fact probably related to the higher frequency of injuries that result in extravasation of saliva to the adjacent connective tissue [11].

In agreement with similar studies reported in the literature, in the present investigation $75.85 \%$ of the cases were diagnosed during the first and second decades of life, $49.42 \%$ of them during the second decade of life. Two

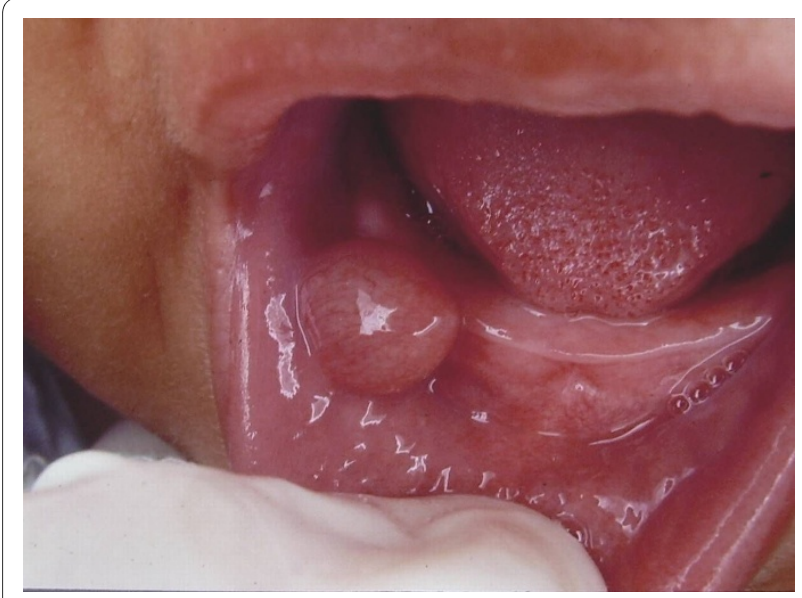

Figure 5 Turgid nodular lesion located on the lower lip of an infant. cases were diagnosed in newborns. Jones et al [9], analyzing 4406 children ranging in age from 0 to 16 years over a period of 30 years (1973-2002), observed 735 (16.68\%) cases of mucoceles.

In the present study, most patients (60.12\%) were females, in agreement with studies showing almost $70 \%$ prevalence of mucocele in women [17]. In contrast, Mathew et al. [20] describe a prevalence of mucocele in $0.16 \%$ of the population studied and the lesion was found only in males. Cataldo and Mosadomi [12], studying 594 cases between 1958 and 1969, observed no gender preference. As regards race, the lesion was more common in white subjects $(124 ; 71,68 \%)$ in accordance to de Camargo Moraes et al. [19].

The most common location of mucoceles is the lower lip. This may be related to the trauma exerted upon the lip, as a result of teeth spatial distribution [3,11]. In the present study, mucoceles were observed on the lower lip in $78 \%$ of the cases, all presenting a history of trauma. Less frequently involved regions included the ventral tongue, floor of the mouth (ranula), hard and soft palate, buccal mucosa, and lingual frenum.

Mucoceles are more frequently treated by surgical excision of the lesion and careful dissection of the adjacent minor salivary glands affected [11,17]. However, recurrence can occur and a new surgical intervention taking the above mentioned care is necessary [11].

In the case of ranulas, treatment consists of surgical removal of the sublingual gland and/or marsupialization. Marsupialization may be performed before definitive excision of the gland in an attempt to permit the formation of an intraoral fistula through which saliva is excreted. This approach requires the removal of the roof of the lesion in order to permit reestablishment of the communication between the gland duct and oral cavity [11].

Yagüe-Garcia et al. [3] compared the results obtained after treatment with scalpel versus $\mathrm{CO}_{2}$ laser. Authors concluded that $\mathrm{CO}_{2}$ laser ablation is rapid and simple. They had postoperative complications and recurrence in the cases treated with conventional surgery. It is important to emphasize that the removed specimen must be microscopically evaluated to confirm the diagnosis, regardless of the technique used [3]. Prognosis is excellent.

\section{Conclusion}

In this study, mucoceles predominated in white female subjects in the second decade of life, with the lower lip being the most frequently affected site.

\section{Competing interests}

The authors declare that they have no competing interests. 


\section{Authors' contributions}

AMH and DCZZ analyzed and interpreted patient's data from the files. IB performed the statistical analysis. LAGC participated in the design of the research. JDA conceived, coordinated and helped to draft the manuscript. All authors read and approved the final manuscript. All authors read and approved the final manuscript.

\section{Acknowledgements}

Patient's parents signed an informed written consent for publication of the manuscript and figures.

\section{Author Details}

'Private Dentist, São Paulo, São Paulo, Brazil, 2Department of Social Science and Pediatric Dentisty, São José dos Campos Dental School, São Paulo State University (UNESP), São José dos Campos, São Paulo, Brazil and ${ }^{3}$ Department of Biosciences and Oral Diagnosis, São José dos Campos Dental School, São Paulo State University (UNESP), São José dos Campos, São Paulo, Brazil

Received: 19 May 2009 Accepted: 7 June 2010

Published: 7 June 2010

\section{References}

1. Anastassov GE, Haiavy J, Solodnik P, Lee H, Lumerman H: Submandibular gland mucocele diagnosis and management. Oral Surg, Oral Pathol, Oral Radiol \& Endod 2000, 89:159-163.

2. Gatti AF, Moretti MM, Cardoso SV, Loyola AM: Mucus extravasation phenomenon in newborn babies: report of two cases. Int J Paed Dent 2001, 11:74-77.

3. Yagüe-García J, España-Tost AJ, Berini-Aytés L, Gay-Escoda C: Treatment of oral mucocele-scalpel versus $\mathrm{CO} 2$ laser. Med Oral Patol Oral Cir Bucal 2009, 14:e469-e474.

4. Granholm C, Olsson Bergland K, Walhjalt H, Magnusson B: Ora mucoceles; extravasation cysts and retention cysts. A study of 298 cases. Swed Dent J 2009, 33:125-30.

5. Dent CD, Svirsky JA, Kenny KF: Large mucous retention phenomenon (mucocele) of the upper lip: case report and review of the literature. Virginia Dent J 1997, 74:8-9.

6. Davis SB, Simon JHS: Mucocele: a potential complication to endodontic surgery. J Endod 1994, 20:515-517.

7. Tran TA, Parlette HL: Surgical pearl: removal of large labial mucocele. $J$ Am Acad Dermatol 1999, 40:760-762.

8. Everson JW: Superficial mucoceles: Pitfall in clinical and microscopic diagnosis. Oral Surg Oral Med Oral Pathol 1988, 66:318-322.

9. Jones AV, Franklin CD: An analysis of oral and maxillofacial pathology found in children over a 30-year period. Int J Paed Dent 2006, 16:19-30

10. Yamasoba T, Tayama N, Syoji M, Fukuta M: Clinicostatistical study of lower lip mucoceles. Head \& Neck 1990, 12:316-320.

11. Baurmash HD: Mucoceles and Ranulas. J Oral Maxillofac Surg 2003, 61:369-378

12. Cataldo E, Mosadomi A: Mucoceles of the oral mucous membrane. Arch Otolaryng 1970, 91:360-365.

13. Delbem ACB, Cunah RF, Vieira AEM, Ribeiro LL: Treatment of mucus retention phenomena in children by the micro-marsupialization technique: case reports. Pediatr Dent 2000, 22:155-158.

14. Ellis SG, Lee NJ, Peckitt NS: Mucous retention cyst of the soft palate: a case presentation. Dent Update 1995, 22:421-422.

15. Jensen $\mathrm{J}$ : Superficial mucoceles of the oral mucosa. Am J Dermatopathol 1990, 12:88-92.

16. Zancopé E, Pereira AC, Ribeiro-Rotta RF, Mendonça EF, Batista AC: Mucocele in posterior dorsal surface of tongue: an extremely rare location. J Oral Maxillofac Surg 2009, 67:1307-1310.

17. Nico MM, Park JH, Lourenço SV: Mucocele in pediatric patients: analysis of 36 children. Pediatr Dermatol 2008, 25:308-311.

18. Meseguer DH, Gálvez EM, Ruiz JÁ: Mucocele de glándula submaxilar. Anales ORL Iber Amer 1996, 3:319-3.

19. de Camargo Moraes P, Bönecker M, Furuse C, Thomaz LA, Teixeira RG, de Araújo VC: Mucocele of the gland of Blandin-Nuhn: histological and clinical findings. Clin Oral Investig 2009, 13:351-353.

20. Mathew AL, PAi KM, Sholapurkar AA, Vengal M: The prevalence of oral mucosal lesions in patients visiting a dental school in Southern India. Indian J Dent Res 2008, 19:99-103.

\section{Pre-publication history}

The pre-publication history for this paper can be accessed here: http://www.biomedcentral.com/1472-6831/10/15/prepub

doi: $10.1186 / 1472-6831-10-15$

Cite this article as: Hayashida et al., Mucus extravasation and retention phenomena: a 24-year study BMC Oral Health 2010, 10:15

\section{Submit your next manuscript to BioMed Central and take full advantage of:}

- Convenient online submission

- Thorough peer review

- No space constraints or color figure charges

- Immediate publication on acceptance

- Inclusion in PubMed, CAS, Scopus and Google Scholar

- Research which is freely available for redistribution

Submit your manuscript at www.biomedcentral.com/submit
C Biomed Central 